\title{
Prehypertension, Hypertension and Associated Risk Factors among Adults Living in the Port City of Boma in the Democratic Republic of the Congo. A Population-Based Cross-Sectional Survey
}

\section{Blaise Makoso Nimi ${ }^{1,2}$, François Lepira Bompeka ${ }^{1}$, Aliocha Nkodila ${ }^{3 *}$, Williams Ilenga ${ }^{2,4}$, Gédeon Long-Longo ${ }^{5}$, Dieudonné Vangu Ngoma ${ }^{5}$, Patrick Kayembe Kalambayi ${ }^{6}$, Eulethère Kintoki Vita ${ }^{1}$, Jean René M'Buyamba-Kabangu $^{1}$ and Benjamin Longo Mbenza $^{1,5}$}

${ }^{1}$ Department of Internal Medicine, University Clinics of Kinshasa, Democratic Republic of the Congo

${ }^{2}$ Faculty of Medicine, Kasa Vubu University of Boma, Democratic Republic of the Congo ${ }^{3}$ Medical Center Cité des Aveugles, Mont Ngafula, Democratic Republic of the Congo ${ }^{4}$ Pathology Department, University Clinics of Kinshasa, Democratic Republic of the Congo ${ }^{5}$ Lomo-Medical Hospital Center, Democratic Republic of the Congo

${ }^{6}$ School of Public Health, Department of Bio-statistics, Democratic Republic of the Congo *Corresponding Author: Aliocha Nkodila, Medical Center Cité des Aveugles, Mont Ngafula, Democratic Republic of the Congo.

\author{
Received: February 13, 2020 \\ Published: April 27, 2020 \\ (C) All rights are reserved by Aliocha \\ Nkodila., et al.
}

\begin{abstract}
Background: The risk for CVD starts to increase at BP levels above 115/75 mmHg. Therefore, early detection of individuals with mild to moderate BP increase could help reducing hypertension-associated CV risk. The present survey was aimed to assess the prevalence of prehypertension and hypertension in adults living in a port City.

Methods: In the present cross-sectional survey, a sample of households was systematically selected from the port City of Boma ant its rural suburb. A total of 3510 adult subjects (2265 men and 1245 women) were included in the study. Demographic, socioeconomic, clinical and biological data were collected using WHO Stepwise questionnaire. Systolic and diastolic BP were as well as heart rate measured for all subjects. Blood examination included only fasting capillary blood glucose taken between 8 - 10 hours a.m. following 12 hours of fasting. Prehypertension and hypertension were defined according to JNC7 guidelines. Logistic regression analysis was used to assess risk factors associated with both conditions. P values $<0.05$ defined the level of statistical significance.

Results: The crude prevalence of prehypertension and hypertension was $11.4 \%$ and $35.5 \%$, respectively. Increased age, overweight and obesity emerged as the main factors associated with both conditions whereas family history of hypertension and smoking were only associated with hypertension.

Conclusion: Prehypertension and hypertension were a common finding in the present survey and associated with lifestyle factors. A strategy based on therapeutic lifestyle changes and pharmacologic therapy (if needed) is awaited.

Keywords: Prehypertension; Hypertension; Prevalence; Risk Factors; Black Africans
\end{abstract}

\section{Introduction}

High blood (HBP) is a major public health challenge and is identified as the foundation of the epidemics of cardiovascular disease (CVD), chronic kidney disease (CKD) and associated morbi-mortality in sub-Saharan Africa (SSA) [1,2]. HBP accounts for one quarter of the global preventable premature death annually $[3,4]$. There is an estimated increase in the prevalence of HBP by $17 \%$ worldwide in the next decade, with the greatest increase in the African region, if effective preventive measures as well as an early detection and management-based strategy are not implemented [5]. The first step in implementing such a strategy implies the assessment of the disease's burden and the identification of associated risk factors in high risk settings for HBP like port cities [5]. With reference to the disease's burden, the risk of developing HBP-related complications has been reported to depend on the level of $\mathrm{BP}$ and starts in all age groups from BP as low as systolic BP (SBP) $115 \mathrm{mmHg}$ and diastolic BP (DBP) $75 \mathrm{mmHg}$ [6]. Indeed, suboptimal SBP > $115 \mathrm{mmHg}$ was reported to be responsible for $62 \%$ of CVD and $42 \%$ of ischemic heart disease (IHD), with little variation by sex [6]. Furthermore, data from observational studies involving more than one million individuals have indicated that death from both IHD and stroke increase progressively and linearly from levels as low as SBP 115 $\mathrm{mmHg}$ and DBP $75 \mathrm{mmHg}$ upward, especially in individuals ranging from 40 to 89 years [6]. These above-mentioned observations prompted the need for new BP classification and Joint National Committee 7 (JNC 7) report on the prevention, detection, evaluation, and treatment of HBP introduced a new BP classification that includes the term "prehypertension" for individuals with BP ranging from 120 to $139 \mathrm{mmHg}$ SBP and 80 to $89 \mathrm{mmHg}$ DBP [7] This new designation was intended to identify those individuals in whom early intervention by adoption of healthy lifestyles could re- 
duce BP, decrease rate of progression of BP to hypertensive levels with age or prevent hypertension entirely [7]. Therefore, reliable population-based data on prehypertension are needed to inform policy decision, especially in SSA, a world region confronted to limited health resources and a less operational health system [8]. Unfortunately, most epidemiological studies still focus on the detection of hypertension with less attention to prehypertension.

Considered as rare even inexistent in the early sixties, hypertension prevalence has attained prevalence rates around $30-40 \%$ in both sex and in urban as well as rural areas of the Democratic Republic of the Congo (DRC) [10-13]. This ever growing hypertension prevalence is contrastingly associated with low awareness and proportion of treated and BP controlled individuals [11,12]. As a consequence, hypertension-related morbidity and mortality has been reported to be very high $[14,15]$ highlighting thus the need for early detection and management of HBP prior to the development HBP-related complications. In this regard, few epidemiological studies have been unfortunately devoted to prehypertension [16].

\section{Aim of the Study}

Therefore, the aim of the present study was to assess the prevalence of both prehypertension and hypertension and to identify associated risk factors among adults living in a port city.

\section{Methods}

\section{Study setting}

The study was conducted in Boma, a port city with a population of 459. 361 inhabitants, located in the province of Kongo Central at about ... Km southwest of Kinshasa, the Capital City. It has mixed urban and rural communities and comprised of three administrative districts and one rural district.

The study used a cross-sectional design. The minimum desired sample size was 384 participants using the Fischer formulae [17]. A multistage sampling strategy was used. The city of Boma includes 3 urban districts and 1 rural district. In all these districts, the lists of existing streets were obtained and 2 streets were selected in each district using simple random sampling strategy. On the streets drawn all the inhabited plots were listed in order to constitute the sampling frame. All the parcels listed with the odd numbers have been selected. In the selected plots, all residents aged 18 or over were invited to participate in the study. A total of 3,510 people were included in the study with a respondent rate of $91,4 \%$.

\section{Data collection}

A local language and pretested version of the World Health Organization (WHO)-STEP surveillance (STEPS) questionnaire (version 3-1) was used with minor adaptation [18]. During the first step, sociodemographic and behavioral information on tobacco and alcohol use, diet, physical activity, history of chronic illnesses were collected. In step 2, physical measurements including weight, height, blood pressure (BP) and waist circumference (WC) were collected using standard procedures measurements and WHO recommended instruments that were regularly calibrated. In step 3, fasting capillary blood glucose was the only biochemical test performed in the present study.

\section{Measures}

The anthropometric measurements such as body weight, waist circumference, height, blood pressure, and pulse rate were collected by well-trained Medical students? Blood pressure was measured using digital blood pressure measurement devices (OMRON MIT5 Connect, Kyoto, Japan) and recorded during household visits following the STEPS methods at the left arm at heart level after a period of 5 minutes of rest). The average of the two measurements were used in the analysis.

Height was measured, while the participants were in an upright position without shoes, by using a flexible tape meter (Hemostyl, Sulzbach, Germany). Body weight was also measured with individuals wearing light clothing or standing without shoes using a digital weighing scale (Deluxe GBS-721; Seca Deutschland, Hamburg, Germany). Body mass index (BMI) was computed as weight in kilograms divided by height in meters squared $\left(\mathrm{Kg} / \mathrm{m}^{2}\right)$. A flexible tape meter was used to measure the waist at the level directly above the iliac crest.

During the household visits, questionnaires on tobacco smoking and chewing, intake of fruit and vegetable and patterns of physical activities were administered. Participants were asked about their fruits and vegetables consumption in a typical week, number of days and the number of servings on those days was collected. Fruits and vegetable consumption was analyzed as number of times per week. The Global Physical Activity Questionnaire Version 2 was used to collect the information on physical activities [19].

\section{Operational definitions}

Prehypertension was defined as having either an SBP of 120 to $139 \mathrm{mmHg}$ and/or DBP of 80 to $89 \mathrm{mmHg}$ - according to JNC7, in individuals who were not on antihypertensive medication [7]. Hypertension was defined as presence of SBP $\geq 140 \mathrm{mmHg}$ and/or DBP $\geq 90 \mathrm{mmHg}$ or self-report of previous diagnosis of hypertension by a healthcare provider or a history of treatment with antihypertensive agents [7]. Overweight and obesity were defined as having a $\mathrm{BMI} \geq 25 \mathrm{Kg} / \mathrm{m}^{2}$ and $\geq 30 \mathrm{Kg} / \mathrm{m}^{2}$, respectively [20]. Waist circumference (WC) was used as surrogate for abdominal obesity, defined as a $W C$ value $>94 \mathrm{~cm}$ in men and $>80 \mathrm{~cm}$ in women [21]. Diabetes was defined as fasting capillary blood glucose $\geq 110 \mathrm{mg} /$ dl or history of antidiabetic treatment [22]. Physical inactivity with reference to global physical activity questionnaire was defined as a total value $<18$ [19]. Hazardous alcohol consumption was defined as a daily consumption of at least $20 \mathrm{~g}$ of alcohol or $>2$ glasses?? for at least one year [23]. Smoking was defined as current use of smoked or smokeless tobacco [24]. According to 2013 - 2014 DRCDemographic and Health Survey (DHS), low, middle and high socioeconomic status (SES) scores were defined as 0 - 3, 4 - 8 and $>9$ respectively [25].

\section{Data analysis}

The data collected was cleaned and entered into a PC to be examined by using SPSS version 24.0 for Windows. Categorical variables were expressed as absolute (n) and relative (in percent) frequency (n) whereas continuous variables with normal and skewed distribution were expressed as mean \pm standard deviation and median (Interquartile range), respectively. A chi-square test was used to examine the association between different categorical variables 
whereas t-test or ANOVA were used for normally distributed continuous variables and Mann U Whitney and Kruskall Wallis tests for continuous variables with skewed distribution. Multivariate logistic regression analysis were performed to assess independent risk factors associated with prehypertension and hypertension. Pvalues of $<0.05$ were considered statistically significant.

\section{Ethical approval}

The study was conducted according to the principles expressed in the Declaration of Helsinki and the protocol for the Non Communicable Disease (NCD) risk factor survey using the World Health Organization STEPwise approach to Surveillance (WHO STEPS) [23] was approved by the Ethical Committee of the Ministry of Health ( $\left.{ }^{\circ} 104 / C N E S / B N / P M M F / 2018\right)$ and the Scientific Board of the Department of Internal Medicine, University of Kinshasa Hospital, Kinshasa School of Medicine. Written informed consent was obtained from the study participants and they had the right to withdraw themselves from the study at any time. The identity of the participants as well as their personal information was kept confidential. Participants incidentally reporting with life-threaten- ing conditions during the period of this survey were immediately referred to the hospitals, and those individuals with new incidence of hypertension were also directed to begin a follow-up treatment at the nearby health facility or a hospital.

\section{Results}

General characteristics of the study population

General characteristics of the study population as a whole and by BP categories are depicted in table 1 . Of the 3510 participants, 1396 (40\%) were males while $2114(60 \%)$ were females. Their mean age was $36,3 \pm 15,9$ years with $43,4 \%, 23 \%, 13,4 \%, 9,6 \%$ and $10,5 \%$ participants aged 18 - 29 years, 30 - 39 years, $40-49$ years, 50 - 59 years and $\geq 60$ years, respectively. Most participants (74.2\%) were recruited from the rural suburb; the proportion of unemployed, married, single, secondary education level and low SES participants was $22.6 \%, 43 \%, 46.6 \%, 58.9 \%$ and $63.5 \%$, respectively. Average levels of SBP, DBP, HR, BMI, WC and capillary blood glucose were $122.2 \pm 21.9 \mathrm{mmHg}, 80.7 \pm 14.9 \mathrm{mmHg}, 80.8 \pm$ $12.1 \mathrm{bpm}, 23.1 \pm 5.7 \mathrm{Kg} / \mathrm{m}^{2}, 81,7 \pm 11,9 \mathrm{~cm}$ and $118,1 \pm 31,1 \mathrm{mg} /$ $\mathrm{dl}$, respectively.

\begin{tabular}{|c|c|c|c|c|c|}
\hline Variables & All $n=3510$ & Normotension $\mathbf{n}$ & Prehypertention $n=399$ & Hypertension $\mathbf{n}$ & $\mathbf{p}$ \\
\hline Age, years & $36,3 \pm 15,9$ & $31.0 \pm 12.4$ & $35.0 \pm 14.0$ & $44.7 \pm 17.6$ & $<0.001$ \\
\hline Age categories, n (\%) & & & & & $<0.001$ \\
\hline $18-29$ years & $1524(43.4)$ & $1063(57.0)$ & $176(44.1)$ & 285 (22.9) & \\
\hline $30-39$ years & $809(23.0)$ & $428(22.9)$ & $102(25.6)$ & $279(22.4)$ & \\
\hline $40-49$ years & $469(13.4)$ & $204(10.9)$ & $54(13.5)$ & $211(16.9)$ & \\
\hline $50-59$ years & $338(9.6)$ & $94(5.0)$ & $39(9.8)$ & $205(16.5)$ & \\
\hline$\geq 60$ years & $370(10.5)$ & $77(4.1)$ & & & 0.001 \\
\hline Gender, n (\%) M & $1396(40)$ & $755(40.5)$ & $186(46.6)$ & $455(36.5)$ & \\
\hline $\mathrm{F}$ & $2114(60)$ & $1111(59.5)$ & $213(53.4)$ & $790(63.5)$ & 0.323 \\
\hline Setting, n (\%) Urban & $904(25,8)$ & $463(24.8)$ & $112(28.1)$ & $329(26.4)$ & \\
\hline Rural & $2606(74,2)$ & $1403(75.2)$ & $287(71.9)$ & $916(73.6)$ & \\
\hline Occupation, n (\%) & & & & & $<0.001$ \\
\hline Senior Staff & $923(26,3)$ & $584(31.30)$ & $104(26.10)$ & $235(18.90)$ & \\
\hline Businessmen & $1187(33,8)$ & $626(33.50)$ & $155(38.80)$ & $406(32.60)$ & \\
\hline Public Servants & $513(14,6)$ & $276(14.80)$ & $62(15.50)$ & $175(14.10)$ & \\
\hline Unemployed & $93(2,6)$ & $15(0.80)$ & $9(2.30)$ & $69(5.50)$ & \\
\hline Marital status, n (\%) & & & & & $<0.001$ \\
\hline Married & $1509(43,0)$ & $696(37.3)$ & $184(46.1)$ & $629(50.5)$ & \\
\hline Divorced & $94(2,7)$ & $39(2.1)$ & $7(1.8)$ & $48(3.9)$ & \\
\hline Widow & $271(7,7)$ & $63(3.4)$ & $17(4.3)$ & $191(15.3)$ & \\
\hline Single & $1636(46,6)$ & $1068(57.2)$ & $191(47.9)$ & $377(30.3)$ & \\
\hline Education level, n (\%) & & & & & $<0.001$ \\
\hline Primary/no & $699(19,9)$ & $306(16.4)$ & $65(16.3)$ & $328(26.3)$ & \\
\hline Secondary & $2069(58,9)$ & $1158(62.1)$ & $249(62.4)$ & $662(53.2)$ & \\
\hline University/Superior & $742(21,1)$ & $402(21.5)$ & $85(21.3)$ & $255(20.5)$ & \\
\hline SES, n (\%) & & & & & 0.051 \\
\hline Low & $2229(63,5)$ & $1206(64.6)$ & $269(67.4)$ & $754(60.6)$ & \\
\hline Middle & $988(28,1)$ & $517(27.7)$ & $99(24.8)$ & $372(29.9)$ & \\
\hline High & $293(8,3)$ & $143(7.7)$ & $31(7.8)$ & $119(9.6))$ & \\
\hline BMI, $\mathrm{Kg} / \mathrm{m}^{2}$ & $23,1 \pm 5,7$ & $22.3 \pm 5.3$ & $23.5 \pm 5.7$ & $24.1 \pm 5.9$ & $<0.001$ \\
\hline $\mathrm{WC}, \mathrm{cm}$ & $81,7 \pm 11,9$ & $79.2 \pm 10.5$ & $81.8 \pm 11.6$ & $85.4 \pm 13.2$ & $<0.001$ \\
\hline SBP, $\mathrm{mmHg}$ & $122,2 \pm 21,9$ & $110.1 \pm 10.1$ & $126.6 \pm 8.3$ & $149.1 \pm 25.8$ & $<0.001$ \\
\hline $\mathrm{DBP}, \mathrm{mmHg}$ & $80,7 \pm 14,9$ & $71.8 \pm 7.7$ & $83.1 \pm 6.5$ & $93.1 \pm 15.7$ & $<0.001$ \\
\hline MAP, $\mathrm{mmHg}$ & $94,5 \pm 16,2$ & $84.6 \pm 7.5$ & $97.6 \pm 3.9$ & $108.4 \pm 17.4$ & $<0.001$ \\
\hline $\mathrm{PP}, \mathrm{mmHg}$ & $41,6 \pm 14,3$ & $38.3 \pm 9.0$ & $43.5 \pm 12.7$ & $45.9 \pm 19.3$ & $<0.001$ \\
\hline HR, bpm & $80,8 \pm 12,1$ & $80.0 \pm 11.9$ & $81.6 \pm 12.2$ & $81.6 \pm 12.2$ & 0.581 \\
\hline Blood glucose, mg/dl & $118,1 \pm 31,1$ & $118.4 \pm 32.5$ & $117.5 \pm 28.7$ & $117.9 \pm 29.7$ & 0.982 \\
\hline
\end{tabular}

Table 1: General characteristics of the study population as a whole and by blood pressure categories according to JNC 7.

Data are expressed as mean \pm standard deviation, absolute (n) and relative (in percent) frequency. Abbreviations: M: Male; F: Female; SES: Socioeconomic Status; BMI: Body Mass Index; WC: Waist Circumference; SBP: Systolic Blood Pressure; DBP: Diastolic Blood Pressure; MAP: Mean Arterial Blood Pressure; PP: Pulse Pressure; HR: Heart Rate; bpm: Beat Per Minute. 
Prehypertension, Hypertension and Associated Risk Factors among Adults Living in the Port City of Boma in the Democratic Republic of the Congo. A Population-Based Cross-Sectional Survey

Table 2 summarizes cardiovascular risk factor profile of the study population as a whole and by BP categories. In the study population as a whole, physical inactivity (57.5\%), alcohol intake (45.3\%), FH-HT (43.6\%), central obesity (38.1\%) and DM (33.9\%) were cardiovascular risk factors most frequently reported by the participants.

\begin{tabular}{|l|c|c|c|c|c|}
\hline \multicolumn{1}{|c|}{ Variables } & All n = 3510 & Normotension n & Prehypertention n = 399 & Hypertension n & p \\
\hline Age,yrs > 55 M/45 F, n (\%) & $760(21.7)$ & $760(21.7)$ & $274(12.1)$ & $486(39.0)$ & $<0.001$ \\
\hline FH-HT, n (\%) & $153(43.6)$ & $1530(43.6)$ & $945(41.7)$ & $585(47.0)$ & 0.003 \\
\hline FH-DM, n (\%) & $392(11.2)$ & $392(11.2)$ & $260(11.5)$ & $132(10.6)$ & 0.232 \\
\hline FH-CVD, n (\%) & $222(6.3)$ & $222(6.3)$ & $138(6.1)$ & $84(6.7)$ & 0.244 \\
\hline Smoking, n (\%) & $515(14.7)$ & $515(14.7)$ & $281(12.4)$ & $234(18.8)$ & $<0.001$ \\
\hline Alcohol intake, n (\%) & $1590(45.3)$ & $1590(45.3)$ & $1010(44.6)$ & $580(46.6)$ & 0.136 \\
\hline Menopause, n (\%) & $557(15.9)$ & $148(7.9)$ & $47(11.8)$ & $362(29.1)$ & $<0.001$ \\
\hline Overweight, n (\%) & $563(16.0)$ & $563(16.0)$ & $277(12.2)$ & $286(23.0)$ & $<0.001$ \\
\hline Obesity, n (\%) & $282(8.0)$ & $282(8.0)$ & $135(6.0)$ & $147(11.8)$ & $<0.001$ \\
\hline Central obesity, n (\%) & $1337(38.1)$ & $1337(38.1)$ & $720(31.8)$ & $617(49.6)$ & $<0.001$ \\
\hline PH-DM, n (\%) & $158(33.9)$ & $158(33.9)$ & $95(25.1)$ & $63(37.1)$ & 0.162 \\
\hline Physical inactivity, n (\%) & $2020(57.5)$ & $2020(57.5)$ & $1245(55.0)$ & $775(62.2)$ & $<0.001$ \\
\hline Consommation graisse, n (\%) & & & & & $<0.001$ \\
\hline Amélioré Chol & $43(1.2)$ & $24(1.3)$ & $4(1.0)$ & $15(1.2)$ & \\
\hline No-optimal Chol & $1268(36.1)$ & $764(40.9)$ & $147(36.8)$ & $357(28.7)$ & \\
\hline Grave Chol & $2199(62.6)$ & $1078(57.8)$ & $248(62.2)$ & $873(70.1)$ & $<0.001$ \\
\hline Consommation fruit and légume, $\mathbf{n}(\%)$ & & & & & \\
\hline Pauvre & $2497(71.1)$ & $1389(74.4)$ & $258(71.4)$ & $823(66.1)$ & \\
\hline Riche & $1013(28.9)$ & $477(25.6)$ & $114(28.6)$ & $422(33.9)$ & \\
\hline
\end{tabular}

Table 2: Cardiovascular risk factor profile of the study population as a whole and by blood pressure categories according to JNC 7. Data are expressed as absolute (n) and relative (in percent) frequency. Abbreviations: yrs: Year; M: Male; F: Female; FH: Family History; HT: Hypertension; DM: Diabetes Mellitus; CVD: Cardiovascular Disease; PH: Personal History.

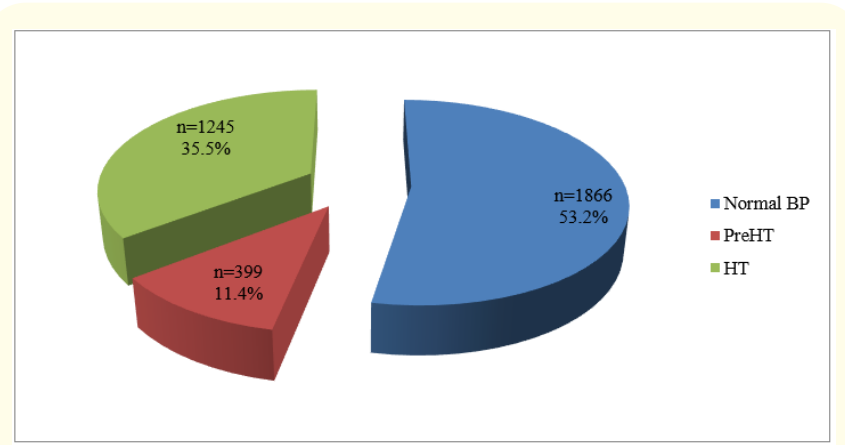

Figure 1: Distribution of study population by blood pressure categories according to JNC7. Abbreviations: BP: Blood Pressure; PreHT: Prehypertension; HT: Hypertension.

\pm 14.0 vs $31.0 \pm 12.4$ years; $\mathrm{p}<0.001)$ and hypertensive $(44.7 \pm$ 17.0 vs $31.0 \pm 12.4$ years; $p<0.001$ ) participants compared to normotensive ones (Table 1). The same picture was observed for the prevalence of prehypertension and hypertension by age categories (Table 1). Prehypertension was more significantly more frequent in men ( 46.6 vs $40.5 \%$; $\mathrm{p}<0.001$ ) whereas hypertension was more frequently encountered in females ( 63.5 vs $59.5 \%$; $p<0.001$ ) compared to male and females normotensive participants, respectively. The proportion of unemployed participants was significantly higher among prehypertensive (2.3 vs $0.8 \%$; $<<0.001$ ) and hypertensive ( 5.5 vs $0.8 \%$; $p<0.001$ ) participants compared to their normotensive counterparts. Similarly, the proportion of married (46.1 vs $37.1 \%$; $\mathrm{p}<0.001$ for prehypertension; 50.5 vs $37.1 \%$; $<<0.001$
Prevalence and clinical profile of prehypertension and hypertension

Prehypertension and hypertension were observed in 399 (11.9\%) and 1245 (35.5\%) participants, respectively (Figure 1). Age was in average significantly increased in prehypertensive (35.0 
Prehypertension, Hypertension and Associated Risk Factors among Adults Living in the Port City of Boma in the Democratic Republic of the Congo. A Population-Based Cross-Sectional Survey

0.025), menopause ( $p=0.013)$, overweight $(p=0.041)$ and obesity $(\mathrm{p}=0.0001)$. In addition to cardiovascular risk factors associated with prehypertension, FH-HT ( $p=0.003)$, smoking ( $p=0.0001)$, personal history $(\mathrm{PH})$ of hyperuricemia $(\mathrm{p}=0.011)$ and central obesity (0.012) emerged as the main cardiovascular risk factors significantly associated with hypertension. In multivariate analysis (Table 4), the strength of the associations observed in univariate analysis with prehypertension persisted for all the cardiovascular risk factors except for menopause. Indeed, the likelihood of being associated with prehypertension was increased around twofold in the presence of increased age (aOR 1,86; 95\%CI 1.10 - 3.14; $\mathrm{p}=0.025)$ ], overweight (aOR 1,54; 95\%CI $1.03-2.04 ; \mathrm{p}=0.032$ ) and obesity (aOR 2.24; 95\%CI 1.46 - 3.43; p = 0.0001), respectively. Except for personal history of hyperuricemia, menopause and central obesity, the strength of the associations observed in univariate analysis with hypertension persisted for all other cardiovascular risk factors. Thus, the likelihood of being associated with hypertension was increased nearly three-fold in the presence of increased age (aOR 2,88; 95\%CI 2.08 - 3.99; $\mathrm{p}=0.0001$ ), smoking (aOR 2,51; 95\%CI $1.21-3.87 ; \mathrm{p}=0.0001)$ and nearly two-fold for FH-HT ((aOR 1,$69 ; 95 \% \mathrm{CI} 1.21-2.64 ; \mathrm{p}=0.021$ ), overweight (aOR 1.67; 95\%CI 1.34 - 3.08; $\mathrm{p}=0.0001$ ), and obesity (aOR 1.82; 95\%CI $1.03-2.85$; $\mathrm{p}=0.030$ ), respectively.

\begin{tabular}{|c|c|c|c|c|}
\hline \multirow[t]{2}{*}{ Variables } & \multicolumn{2}{|r|}{ PreHT } & \multicolumn{2}{|r|}{ HT } \\
\hline & $\mathbf{p}$ & OR $(95 \% \mathrm{CI})$ & $\mathbf{p}$ & OR $(95 \% \mathrm{CI})$ \\
\hline \multicolumn{5}{|c|}{ Age, yrs $\geq 55 \mathrm{M} / \geq 45 \mathrm{~F}$} \\
\hline No & & 1 & & 1 \\
\hline Yes & 0,025 & $1,66(1,04-1,79)$ & 0,000 & $4,65(3,93-5,52)$ \\
\hline \multicolumn{5}{|l|}{ FH-HT } \\
\hline No & & & & 1 \\
\hline Yes & - & - & 0,003 & $1,95(1,08-3,42)$ \\
\hline \multicolumn{5}{|l|}{ Smoking } \\
\hline No & & & & 1 \\
\hline Yesi & - & - & 0,000 & $1,63(1,35-1,98)$ \\
\hline \multicolumn{5}{|l|}{ PH-Hyperuricemia } \\
\hline No & & & & 1 \\
\hline Yes & - & - & 0,011 & $2,13(1,67-2,72)$ \\
\hline \multicolumn{5}{|l|}{ Menopause } \\
\hline No & & 1 & & 1 \\
\hline Yes & 0,013 & $1,55(1,10-2,19)$ & 0,000 & $4,35(3,59-5,27)$ \\
\hline \multicolumn{5}{|l|}{ Overweight } \\
\hline No & & 1 & & 1 \\
\hline Yes & 0,041 & $1,79(1,01-2,88)$ & 0,000 & $2,14(1,78-2,57)$ \\
\hline \multicolumn{5}{|l|}{ Obesity } \\
\hline No & & 1 & & 1 \\
\hline Yes & 0,000 & $2,33(1,59-3,40)$ & 0,000 & $2,11(1,65-2,70)$ \\
\hline \multicolumn{5}{|l|}{ Central obesity } \\
\hline No & & & & 1 \\
\hline Yes & - & - & 0,012 & $2,11(1,83-2,43)$ \\
\hline
\end{tabular}

Table 3: Cardiovascular risk factors associated with prehypertension and hypertension in univariate analysis. Abbreviations : PreHT: Prehypertension; HT: Hypertension; yrs: Years; M: Male; F: Female; OR: Odds Ratio; CI: Confidence Interval; FH: Family History; PH: Personal History.

\section{Discussion}

The main findings of the present survey are as follows. First, nearly 1 patient out of 10 and 4 patients out of 10 presented with prehypertension and hypertension, respectively. Second, prehypertension and hypertension were more frequent in women than men. Third, increased age, overweight and obesity emerged as common independent cardiovascular risk factors significantly associated with both prehypertension and hypertension whereas family history of hypertension and smoking were specifically associated with hypertension.
One patient out of 10 in the present survey presented with BP values defining prehypertension. The prevalence of prehypertension found in the present survey is lower that of $30.3 \%$ reported by Bayauli., et al. [16] in urban adults aged $\geq 20$ years from Kinshasa, the capital City of the Democratic Republic of the Congo. It is also lower that of $29.8 \%, 30 \%, 31.0 \%, 37.6 \%, 49.0 \%$ and $58.7 \%$ and $66.1 \%$ reported in a study conducted in four sub-Saharan African countries (Nigeria, South Africa, Tanzania, Uganda) [26], Yaounde/ Cameroon [27], Uganda [28], Kenya [29], Ghana [30], Nigeria [31] and in a study conducted in the Republic of the Congo and Central 
Prehypertension, Hypertension and Associated Risk Factors among Adults Living in the Port City of Boma in the Democratic Republic of the Congo. A Population-Based Cross-Sectional Survey

\begin{tabular}{|c|c|c|c|c|}
\hline \multirow{2}{*}{ Variables } & \multicolumn{2}{|r|}{ PreHT } & \multicolumn{2}{|r|}{ HT } \\
\hline & $\mathbf{p}$ & aOR $(95 \% \mathrm{CI})$ & $\mathbf{p}$ & aOR (95\%CI) \\
\hline \multicolumn{5}{|c|}{ Age, yrs $\geq 55 \mathrm{M} / \geq 45 \mathrm{~F}$} \\
\hline No & & 1 & & 1 \\
\hline Yes & 0.021 & $1.86(1.10-3.14)$ & 0.000 & $2.88(2.08-3.99)$ \\
\hline \multicolumn{5}{|l|}{ FH-HT } \\
\hline No & & & & 1 \\
\hline Yes & - & - & 0.021 & $1.69(1.21-2.64)$ \\
\hline \multicolumn{5}{|l|}{ Smoking } \\
\hline No & & & & 1 \\
\hline Yes & - & - & 0.000 & $2.51(1.21-3.87)$ \\
\hline \multicolumn{5}{|c|}{ PH-Hypeuricemia } \\
\hline No & & & & 1 \\
\hline Yes & - & - & 0.095 & $1.27(0.96-1.69)$ \\
\hline \multicolumn{5}{|l|}{ Menopause } \\
\hline No & & 1 & & 1 \\
\hline Yes & 0.382 & $1.32(0.71-2.45)$ & 0.864 & $1.03(0.72-1.49)$ \\
\hline \multicolumn{5}{|l|}{ Overweight } \\
\hline No & & 1 & & 1 \\
\hline Yes & 0.032 & $1.54(1.03-2.04)$ & 0.000 & $1.67(1.34-2.08)$ \\
\hline \multicolumn{5}{|l|}{ Obesity } \\
\hline No & & 1 & & 1 \\
\hline Yes & 0.000 & $2.24(1.46-3.43)$ & 0.030 & $1.82(1.03-2.85)$ \\
\hline \multicolumn{5}{|c|}{ Central obesity } \\
\hline No & & & & 1 \\
\hline Yes & - & - & 0.236 & $1.15(0.91-1.46)$ \\
\hline
\end{tabular}

Table 4: Cardiovascular risk factors associated with prehypertension and hypertension in multivariate analysis.

Abbreviations: PreHT: Prehypertension; HT: Hypertension; aOR: Adjusted Odds Ratio; CI: Confidence Interval; yrs: Years; M: Male; F: Female; FH: Family History; PH: Personal History.

African Republic [32], respectively. Hypertension was observed in nearly 4 out of 10 participants in the present survey. This prevalence was lower that of $40.8 \%$ reported in the neighbor port City of Matadi [12] and higher than that of 30.9\% [16] and 18 - 19\% found in Kinshasa, the capital City and Bukavu, a southwestern DRC City [11]. With reference to sub-Saharan African studies, the observed prevalence of hypertension was nearly similar to that of 36.9\% reported by Guwatudde., et al. [26] in a cross-sectional study conducted in four sub-Saharan African countries. However, it was lower that of 55.3\%, 53.6\% and 49\% found in South Africa [29], Kenya [29] and Ghana [30] respectively and lower that of $28.5 \%, 18.0 \%$ and $2.8 \%$ reported in Uganda [28], Angola [33] and Cameroon [27], respectively. The disparity in prevalence of prehypertension and hypertension between studies could be explained by differences in population studied, sample size and methodology used as well as geographical distribution of cardiovascular risk factors. This could also be explained by differences in the level and the speed of the epidemiological transition to which are confronted sub-Saharan African countries [34].

Increased age, overweight and obesity emerged as common independent cardiovascular risk factors significantly associated with both prehypertension and hypertension. Our finding of an association of increased aged and overweight/obesity with high BP agrees with previous reports from DRC $[10,11]$ and other subSaharan African countries [26,28,31]. Bayauli., et al. [16] reported that the probability of both prehypertension and hypertension was increased in participants with overweight/obesity (OR 1.666; 95\%CI 1.146 - 2.422 for prehypertension; OR 2.263; 95\%CI 4.561 - 10.706 for hypertension; increased age ( $\geq 55$ years) was associated only with hypertension (OR 6.988; 95\%CI 4.561 - 10.706). Similarly, to Bayauli., et al, Katchunga., et al. [11] found in Bukavu, a southwestern City of DRC that the potential risk of hypertension was increased by age $>40$ years (OR 5.5) and overweight/obesity (OR 1.2). BMI and age were also associated with hypertension in a cross-sectional study conducted in four sub-Saharan African countries (Nigeria, South Africa, Tanzania, Uganda) [26]. In a study from Nigeria, Ononamadu., et al. [35] reported that anthropometric indices studied increased from normotension, through prehypertension. In addition, anthropometric indices studied were significantly correlated with systolic and diastolic BP and BMI (cut-off $24.49 \mathrm{Kg} / \mathrm{m}^{2}$, AUC $=0.698$ for prehypertension; cut-off $23.62 \mathrm{Kg} /$ $\mathrm{m}^{2}$, AUC $=0.659$ for hypertension) as well as WC (cut-off $91.44 \mathrm{~cm}$, AUC $=0.692$ for prehypertension; cut-off $82.55 \mathrm{~cm}$, AUC $=0.645$ for hypertension) showed the highest potential to predict prehypertension and hypertension. Increased age is one of the strongest 
risk factors for the development and progression of hypertension $[36,37]$. Indeed, the ageing process can increase BP through several mechanisms including insulin resistance/hyperinsulinemia and subsequent activation of the sympathetic nervous system and renin angiotensin aldosterone system, clustering of multiple risk cardiovascular risk factors, oxidative stress and subsequent inflammation and endothelial dysfunction, increased renal proximal tubular sodium and water reabsorption mediated by the activation of sodium-proton exchanger [36,37]. Like aging, overweight and obesity also can increase BP through insulin resistance/hyperinsulinemia and their subsequent hemodynamic, metabolic and renal consequences [38].

Family history of hypertension and smoking were specifically associated with hypertension. Family history of hypertension as a surrogate marker of genetic cardiovascular risk factor does translate the contribution of genetic predisposition to the increased prevalence of hypertension observed in the present survey. Indeed, it has been reported that traditional risk factors do not fully explained the ever growing prevalence of hypertension in low and middle income countries including sub-Saharan African countries [39]; thus, other factors of environmental or genetic origin can contribute to this increased prevalence. Among genetic factors, Apolipoprotein L1 (Apol1) gene variants G1 and G2, in homozygous (G1/G1, G2/G2) or heterozygous (G1/G2) compounds, has been reported to increase the risk of hypertension and hypertension-related nephropathy in Afro-Americans as well as in sub-Saharan Africans [39]. In DRC, a recent study by Sumaili., et al. [40] reported an association between G1/G2 variants and BP. The mechanisms underlying the effects ApoL1 variants on BP remain not fully elucidated; however, APOL1 protein expression being observed in vascular media of preglomerular resistance vessels in diseased kidneys, but not in normal kidneys, it will be interesting to see whether vascular smooth muscle expression of APOL1 is associated with BP levels [41]. Smoking was also associated with hypertension in the present study. The association of smoking with increased is a well-known phenomenon and rely upon the generation of oxidative stress and subsequent inflammation and endothelial dysfunction as well as the activation of the sympathetic nervous system and renin angiotensin aldosterone system [42].

The interpretation of the results of the present survey should take into account of some limitations. First, the cross-sectional design of the survey precludes the establishment of any temporal relationship between the outcome and the variables of interest. Second, the unique measurement of the variables of interest could have under- or overestimated their true values and the prevalence of prehypertension and hypertension. Third, other factors usually associated with hypertension such as blood lipids were not measured.

\section{Conclusion}

The present survey in the port City of Boma showed that nearly one participant out of ten and four participants out of ten had prehypertension and hypertension, respectively with increased age, overweight and obesity as common cardiovascular risk factors associated with the two conditions. A strategy based on therapeutic lifestyle changes (TLC) for prehypertension and TLC and pharmacological treatment for hypertensives with increased global cardiovascular risk is needed.

\section{Conflict of Interest}

None.

\section{Acknowledgements}

The management committee of Kasa Vubu University, Nkongo mabiala, Phemba mabemba, Mvuezolo ndenda and Nkambu nlandu.

\section{Author's Contribution}

BMN participated in survey conception and data collection and management; drafted the manuscript.

FLB participated in survey conception and data analysis; revised the manuscript.

AN conducted data analysis and revised the manuscript.

WI revised the manuscript.

PKK participated in survey conception and revised the manuscript.

EKV revised the manuscript.

JRM participated in survey conception and revised the manuscript.

\section{Bibliography}

1. Cooper RS., et al. "High blood pressure: the foundation for epidemic cardiovascular disease in African populations". Ethnicity and Disease 13-2.2 (2003): S48-S52.

2. Sumaili E., et al. "Screening for proteinuria and chronic kidney disease risk factors in Kinshasa: A World". Kidney Day Study 110 (2008): c220-c228.

3. Bhatt DL., et al. "International prevalence, recognition and treatment of cardiovascular risk factors in out patients with atherothrombosis". Journal of the American Medical Association 295 (2006): 180-189.

4. Gunaranthne A., et al. "Secular trends in the cardiovascular risk profile and mortality of stroke admissions in an innercity, multiethnic population in the United Kingdom 1997- 2005". Journal of Human Hypertension 22 (2008): 18-23.

5. World Health Organization (WHO), author. "World Health Statistics". Geneva WHO (2009).

6. Lewington S., et al. "Age-specific relevance of usual blood pressure to vascular mortality: a meta-analysis of individual data for one million adults in 61 prospective studies". Lancet 360 (2002): 1903-1913.

7. World Health Organization. "Reducing risk, promoting healthy life”. Geneva, Switzerland: World Health Report (2002). 
8. Chobanian AV., et al. "The Seventh Report of the Joint National Committee on Prevention, Detection, Evaluation, and Treatment of High Blood Pressure: the JNC 7 report". Journal of the American Medical Association 289 (2003): 2560-2572.

9. Bayauli P., et al. "Cardiovascular risk factors among the inhabitants of an urban Congolese community: results of the Vitaraa Study On behalf of the VITARAA". IJC Metabolic and Endocrine 4 (2014): 33-38.

10. Bayauli MP., et al. "Trends in prevalence of obesity and hypertension in an urban Congolese community". Journal Epidemiological Research 4.1 (2018): 33-40.

11. Katchunga PB., et al. "The trend in blood pressure and hypertension prevalence in the general population of South Kivu between 2012 and 2016: Results from two representative cross-sectional surveys- The Bukavu observational study". PLoS ONE 14.8 (2012): e0219377.

12. Kianu B., et al. "Rates of hypertension prevalence, awareness, treatment, and control in Congolese South West Port City. The influence of gender according to groups". Global Journal of Medical Research 15.1 (2015): 1-8.

13. M'Buyamba - Kabangu J., et al. "Blood pressure in Bantu of Zaïre: epidemiological aspects". Trop Cardiology 13 (1987): 113-120.

14. Lepira FB., et al. "Correlates of target organ damage among black patients with arterial hypertension". Annals of African Medicine 2.3 (2009): 157-163.

15. M'Buyamba-Kabangu JR., et al. "In-Hospital Mortality Among Black Patients Admitted for Hypertension-Related Disorders in Mbuji Mayi, Congo". American Journal of Hypertension 22.6 (2009): 643-648.

16. Bayauli PM., et al. "Prehypertension and hypertension, and associated cardiovascular risk factors among adult Congolese urban dwellers: results of the Vitaraa study". World Journal of Cardiovascular Diseases 4.8 (2014): 390-398.

17. Atoba B., et al. "Prévalence, connaissance et degré de contrôle de l'hypertension artérielle à Kisangani, RD Congo". Kis Medicine 5.2 (2014): 86-93.

18. World Health Organization. "Global action plan for the prevention and control of non communicable diseases 2013-2020". Geneva: World Health Organization (2013).

19. World Health Organization. "Global Physical Activity Questionnaire (GPAQ)". Geneva, Switzerland.

20. World Health Organization (WHO). "The problem of overweight and obesity: preventing and managing the global epidemic". Report Series 894; Geneva WHO (2000): 537.
21. Alberti KG., et al. "Metabolic syndrome - a new world-wide definition. A Consensus Statement from the International Diabetes Federation". Journal of Diabetes Medicine 5.5 (2006): 469-480.

22. "Report of the Expert Committee on the diagnosis and classification of diabetes mellitus". Diabetes Care 26.1 (2003): S5-S20.

23. Takeshi K, laria P, Maufroy N, Jean philippe D, Isabelle M Fakher $\mathrm{N}$, et al. Hypertension artérielle et pression pulsée. Mt cardio. 2006 Sept; 2 (5): 493-501.

24. Orth SR., et al. "Smoking as a risk factor for end-stage renal failure in men with primary renal disease". Kidney International 54 (2008): 926-931.

25. "2013-2014 Democratic Republic of the Congo Demographic and Health Survey (DHS)". Ministry of Heath and Ministry of Planification, rapport préliminaire Mai (2014).

26. Guwatudde D., et al. "The burden of hypertension in sub-Saharan Africa: a four-country cross sectional study". BMC Public Health 15 (2015): 1211.

27. Nansseu JR., et al. "Prevalence of major cardiovascular disease risk factors among a group of sub-Saharan African young adults: a population-based cross-sectional study in Yaoundé, Cameroon". BMJ Open 9.10 (2019): e029858.

28. Nuwaha F and Musinguzi G. "Pre-hypertension in Uganda: a cross-sectional study". BMC Cardiovascular Disorders 13 (2013): 101.

29. Irazola EZ. "Hypertension Prevalence, Awareness, Treatment, and Control in Selected Communities of Nine Low- and Middle Income Countries: Results From the NHLBI/UHG Network of Centers of Excellence for Chronic Diseases". Global Heart 11.1 (2016): 47-59.

30. Owiredu EW., et al. "Demographic and Lifestyle Predictors of Prehypertension: A Cross-Sectional Study among Apparently Healthy Adults in Kumasi, Ghana". BioMed Research International (2019):1764079.

31. Isezuo SA., et al. "Prevalence, associated factors and relationship between prehypertension and hypertension: a study of two ethnic African populations in Northern Nigeria". Journal of Human Hypertension 25.4 (2011): 224-230.

32. Pilleron S., et al. "EPIDEMCA group. Prevalence, awareness, treatment, and control of hypertension in older people in Central Africa: the EPIDEMCA study". Journal of the American Society of Hypertension 11.7 (2017): 449-460.

33. Pedro JM., et al. "Prevalence, awareness, treatment, and control of hypertension, diabetes and hypercholesterolemia among adults in Dande municipality, Angola". Cardiovascular Journal of Africa 29.2 (2018): 73-81. 
34. Kuate Defo B. "Demographic, epidemiological and health transitions: are they relevant to transition health patterns in Africa". Global Health Action (2014): 7-22443.

35. Ononamadu CJ., et al. "Comparative analysis of anthropometric indices of obesity as correlates and potential predictors of risk for hypertension and prehypertension in a population in Nigeria". Cardiovascular Journal of Africa 28.2 (2017): 92-99.

36. Ramos R., et al. "The role of aging in cardiovascular risk factor clustering in non-diabetic population free of coronary heart disease". Journal of Clinical Epidemiology 109.23 (2004): III15-19.

37. Plante GE. "Impact of aging on the body's vascular system". Metabolism 52.10 (2003): 31-35.

38. Reaven GM., et al. "Hypertension and associated metabolic abnormalities. The role of insulin resistance and the sympathoadrenal system". The New England Journal of Medicine 334.2 (1996): 374-381.

39. Freedman BI., et al. "APOL1-Associated Nephropathy: A Key Contributor to Racial Disparities in CKD". American Journal of Kidney Diseases 72.5 (2018): S8-S16.

40. Sumaili EK., et al. "G1 is the major APOL1 risk allele for hypertenstion-attributed nephropathy in Central Africa". Clinical Kidney Journal 12.2 (2018): 188-195.

41. Nadkarni GN., et al. "Apolipoprotein L1 variants and Blood Pressure Traits in African Americans". Journal of the American College of Cardiology 69.12 (2017): 1564-1574.

42. Madika AL and Mounier-Vehier. "Smoking and blood pressure: a complex relationship". La Presse Médicale 46.7-8 (2017): 697-702.

\section{Assets from publication with us}

- Prompt Acknowledgement after receiving the article

- Thorough Double blinded peer review

- Rapid Publication

- Issue of Publication Certificate

- High visibility of your Published work

Website: https://www.actascientific.com/

Submit Article: https://www.actascientific.com/submission.php Email us: editor@actascientific.com

Contact us: +91 9182824667 